\title{
Critically Assessing the Haiti Earthquake Response and the Barriers to Quality Orthopaedic Care
}

\author{
Daniel B. Sonshine BA, Amber Caldwell BA, \\ Richard A. Gosselin MD, MSc, MPH, FRCS(C), \\ Christopher T. Born MD, R. Richard Coughlin MD, MSc
}

Received: 17 November 2011/Accepted: 21 March 2012/Published online: 10 April 2012

(C) The Association of Bone and Joint Surgeons (B) 2012

\begin{abstract}
Background Although numerous authors have described surgical experiences following major disasters, little is

One of the authors (CTB) is a consultant for Stryker Orthopaedics (Mahwah, NJ, USA) and IlluminOss Medical, Inc (East Providence, RI, USA); owns stock from BioIntraface (Riverside, RI, USA) and IlluminOss; has received research funding from the Airlift Research Foundation (Pittsburgh, PA, USA) and the Stein-Bellet Foundation (Philadelphia, PA, USA); and has received research materials from Stryker Orthopaedics. The remaining authors certify that they, or a member of their immediate family, have no commercial associations (eg, consultancies, stock ownership, equity interest, patent/licensing arrangements, etc) that might pose a conflict of interest in connection with the submitted article.

All ICMJE Conflict of Interest Forms for authors and Clinical Orthopaedics and Related Research editors and board members are on file with the publication and can be viewed on request.

Each author certifies that his or her institution approved the human protocol for this investigation, that all investigations were conducted in conformity with ethical principles of research, and that informed consent for participation in the study was obtained.

All work was performed at the Orthopaedic Trauma Institute, San Francisco, CA, USA.
\end{abstract}

Electronic supplementary material The online version of this article (doi:10.1007/s11999-012-2333-4) contains supplementary material, which is available to authorized users.

\section{B. Sonshine}

Weill Cornell Medical College, New York, NY, USA

D. B. Sonshine ( $₫)$, R. A. Gosselin

Institute for Global Orthopaedics and Traumatology, University

of California, San Francisco, San Francisco, CA, USA

e-mail: sonshined@orthosurg.ucsf.edu

D. B. Sonshine, A. Caldwell, R. A. Gosselin, R. R. Coughlin Orthopaedic Trauma Institute, San Francisco General Hospital, 2550 23rd Street, Building 9, 2nd Floor, San Francisco,

CA 94110, USA known regarding the needs of and barriers to care faced by surgeons during such disasters.

Questions/purposes We therefore (1) identified and compared recurrent interview themes essential to the disaster response following the 2010 Haiti earthquake; (2) determined the difference in reported disaster equipment management task difficulty between disaster-trained and untrained volunteers; and (3) approximated the quantity of various procedures performed.

Methods We conducted 14 interviews with selected orthopaedic surgeon volunteers. We also invited the 504 members of the American Academy of Orthopaedic Surgeons (AAOS), who registered as Haiti earthquake volunteers, to complete an online survey; 174 (35\%) completed the survey and $131(26 \%)$ were present in Haiti during the 30 days after the earthquake. Recurrent interview themes were identified, quantified, and compared using Poisson regression analysis. The difference in disaster equipment management difficulty scores was determined with a Wilcoxon rank-sum test.

Results Of 10 recurrent interview themes, group organization (31 occurrences) was mentioned much more often than all but two of the remaining nine themes. Compared with disaster-untrained respondents, equipment management

\section{A. Caldwell, R. R. Coughlin}

Department of Orthopaedic Surgery and Institute for Global Orthopaedics and Traumatology, University of California,

San Francisco, San Francisco, CA, USA

\section{R. A. Gosselin}

School of Public Health at University of California,

Berkeley, Berkeley, CA, USA

\section{T. Born}

Department of Orthopaedic Surgery, Brown University and Rhode Island Hospital, Providence, RI, USA 
tended to be less challenging for disaster-trained respondents. Transporting to the treatment site and security during storage at the site were less challenging (19.5\% and $16.5 \%$ decreases, respectively). Revision surgeries, guillotine amputations, fasciotomies, and internal fixations, suggestive of inappropriate disaster care, were frequently reported.

Conclusions Organizational and training barriers obstructed orthopaedic care delivery immediately after the Haiti earthquake. Disaster training and outcomes require further study to improve care in future catastrophes.

\section{Introduction}

In the weeks and months after the Haiti earthquake of January 2010, hundreds of international organizations, nongovernmental organizations (NGOs), military agencies, and academic institutions responded with resources and services $[8,13,42,56]$. With the help of the United Nations, the US government mobilized medical-surgical response teams within 24 hours of the earthquake [8]. The Department of Health and Human Services' (HHS) National Disaster Medical System (NDMS), in particular, deployed three international medical-surgical response teams and five US disaster medical assistance teams in addition to more than 30 US military ships, Air Force Special Operations Command assets, and US Army resources under the umbrella of the Department of Defense [8, 36, 45, 56].

Before the earthquake, there was already a critical need for surgical and orthopaedic services in Haiti [20, 30]. Owing to this preexisting need and the magnitude of the natural disaster, a coordinated and effective surgical response was essential for this resource-poor country in the aftermath of the earthquake [42]. The initial volunteers who arrived reported the majority of injuries were orthopaedic: crush injuries, open and closed fractures, and compartment syndromes [22, 52, 56, 57]. Some of the deployed orthopaedic surgeons documented these experiences, recording injury patterns, caseload, procedures performed, and short-term outcomes data [3, 14, 16, 34, 37, 40, 56]. These accounts, however, do not measure the barriers to quality surgical care delivery faced by the orthopaedic community.

More than 2 years after the Haiti earthquake of January 2010, there remains the same dearth of literature assessing the care delivery challenges faced by volunteers [5]. Developing tools to assess these needs in times of humanitarian crises can be useful when it is necessary to allocate limited resources and optimize relief efforts [13, 46]. Response to future disasters could be improved by clarifying the barriers to care reported by volunteer orthopaedic surgeons arriving soon after Haiti's 2010 earthquake.
Therefore, our purpose was to qualitatively assess the needs of and barriers to care faced by orthopaedic surgeons who volunteered in Haiti within 30 days of the earthquake. We (1) identified and compared recurrent interview themes essential to the disaster response; (2) determined the difference in reported disaster equipment management task difficulty between disaster-trained and untrained volunteers; and (3) approximated the quantity of various procedures performed.

\section{Materials and Methods}

Within 3 months of the earthquake, we conducted 14 qualitative interviews with selected volunteer orthopaedic surgeon key informants from Haiti, US private practices, and relief organizations affiliated with the US military/ government, fracture care NGOs, or academic/university centers. Based on author expert opinion (RG and RRC), these key informants were selected as representatives of the various responding organizations that had experience with orthopaedic care delivery in Haiti before the earthquake. One interviewer (AC) conducted interviews in person or by telephone within 3 months of the key informants' response to Haiti. Interview questions were open-ended and reflected domains similar to those of the survey, including (1) expectations, (2) preparedness, (3) experience on the ground, (4) reflections, and (5) documentation and media (Appendix 1). A blinded research assistant initially recorded and transcribed the interviews. Interviews were conducted until saturation, whereby the interviewer determines that "no new categories or relevant themes are emerging' [15]. Interview data analysis then was conducted according to the approach of thematic analysis, which is rooted in the constant comparative technique of grounded theory $[12,15,23,26,29]$. This method is used in interview-based qualitative medical, orthopaedic, and even disaster research to assess barriers and needs of a study group [6, 17, 24, 31, 32, 38, 54]. Fundamentally, this iterative process involves coding of transcribed interview data into thematic categories. As transcripts are reviewed the coded sections are constantly compared with other transcripts to ensure consistency of the coding system and to adapt it to newly emerging themes. Two research assistants with different backgrounds coded the transcripts to increase the depth and breadth of the analysis and findings [12]. To resolve discrepancies, the two reviewers met until consensus was achieved. Interviews were reviewed and analyzed twice by each reviewer.

In addition to the interviews, in March 2010, the American Academy of Orthopaedic Surgeons (AAOS), per our request, identified from their database all 504 orthopaedic surgeons who registered as volunteers after the Haiti 
earthquake. The AAOS invited these individuals to complete our anonymous online survey. The survey was designed to assess needs of orthopaedic surgeon volunteers and barriers to orthopaedic care by exploring five major domains, including (1) demographics, (2) predeployment information, (3) experiences on the ground, (4) personal health, and (5) documentation and overall reflections (Appendix 2, supplemental materials are available with the online version of CORR). As the disaster literature lacks any similar form of provider-based assessment, these domains were chosen with the expert opinion of two of the authors (RG and RRC) to reflect barriers to care at different times after the earthquake. The assessment is based on the authors' prior experiences with orthopaedic disaster relief in resource-poor settings. Between March and May 2010, 174 of the 504 AAOS members (35\%), who registered as Haiti volunteers, consented to and completed the survey. It was available online for 60 days. We excluded from this study 43 orthopaedic surgeon respondents who were not present within the first 30 days after the earthquake, January 12 to February 11, 2010, yielding a study population of $131(26 \%)$ orthopaedic surgeons who volunteered within the first 30 days of the earthquake. Of these 131 orthopaedic surgeon survey respondents, $112(86 \%)$ respondents were male, eight $(6 \%)$ respondents were female, and 11 $(8 \%)$ respondents were unidentified (Table 1). The mean age for this study population was 40 years for women and 46 years for men. Based on arrival and departure data, by the end of the first week, 19 (15\%) surgeons reported they had arrived in Haiti (Fig. 1). A maximum of 56 (43\%) surgeons were in Haiti by the end of the second week.

Respondents were grouped by data collected regarding the presence of prior disaster training. Prior disaster training was defined as any prior "formal training in disaster management" (Appendix 2, supplemental materials are available with the online version of CORR). We then compared the 96 untrained respondents with the 32 trained respondents with respect to their degree of difficulty performing seven disaster equipment management tasks including plane unloading, transporting to treatment site, security during transport, security during storage at the site, installing equipment, maintaining equipment, and managing distribution. The degree of difficulty performing these tasks was assessed on a three-point Likert scale $(1=$ not a challenge, $\quad 2=$ moderately challenging, $3=$ very challenging).

In addition, conservative estimates of various procedures performed were generated from data obtained in the survey. These estimates are based on the lower limit of respondent group estimates. For example, if a respondent selected " $1-5$ " or " $6-10$ " procedures performed, only one or six procedures were documented for the conservative estimate, respectively.
Table 1. Study population and predeployment data

\begin{tabular}{|c|c|c|}
\hline Demographic & $\begin{array}{l}\text { Number of } \\
\text { respondents }\end{array}$ & $\begin{array}{l}\text { Percentage } \\
\text { of study } \\
\text { population (\%) }\end{array}$ \\
\hline \multicolumn{3}{|l|}{ Gender } \\
\hline Male & 112 & 86 \\
\hline Female & 8 & 6 \\
\hline Unidentified & 11 & 8 \\
\hline \multicolumn{3}{|l|}{ Practice type } \\
\hline Private practice & 67 & 51 \\
\hline University faculty & 40 & 31 \\
\hline Resident in training & 8 & 6 \\
\hline Retired & 6 & 5 \\
\hline International & 5 & 4 \\
\hline Multispecialty group & 3 & 2 \\
\hline US military & 2 & 2 \\
\hline \multicolumn{3}{|l|}{ Decision date } \\
\hline 1st day & 12 & 9 \\
\hline$<1$ week & 104 & 79 \\
\hline$>1$ week & 13 & 10 \\
\hline \multicolumn{3}{|l|}{ Supplies } \\
\hline Nothing & 13 & 10 \\
\hline Surgical equipment & 108 & 82 \\
\hline Medication & 76 & 58 \\
\hline Implants & 72 & 55 \\
\hline Other & 40 & 31 \\
\hline \multicolumn{3}{|l|}{ Accompanying personnel } \\
\hline $\begin{array}{l}\text { Additional orthopaedic } \\
\text { surgeons }\end{array}$ & 83 & 63 \\
\hline Other surgeon & 70 & 53 \\
\hline Anesthesiologist & 76 & 58 \\
\hline Nurse & 89 & 68 \\
\hline Operating room technician & 43 & 33 \\
\hline Ancillary staff & 60 & 46 \\
\hline Other physician & 52 & 40 \\
\hline $\begin{array}{l}\text { Affiliated with a preexisting } \\
\text { organization }\end{array}$ & 107 & 82 \\
\hline \multicolumn{3}{|l|}{ Credentials } \\
\hline NDMS/IMSuRT & 6 & 5 \\
\hline Military & 5 & 4 \\
\hline Other & 10 & 8 \\
\hline $\begin{array}{l}\text { Prior disaster management } \\
\text { training }\end{array}$ & 32 & 24 \\
\hline Prior disaster experience & 49 & 37 \\
\hline
\end{tabular}

NDMS = National Disaster Medical System; IMSuRT = International Medical Surgical Response Team.

Because count data were obtained in the interview portion of the study, a Poisson regression analysis then was conducted to determine whether the most recurrent theme was discussed much more often than the other generated themes. This Poisson regression is a conservative analysis 
Fig. 1 A graph shows the number of volunteer orthopaedic surgeon respondents in Haiti in the days after the earthquake.

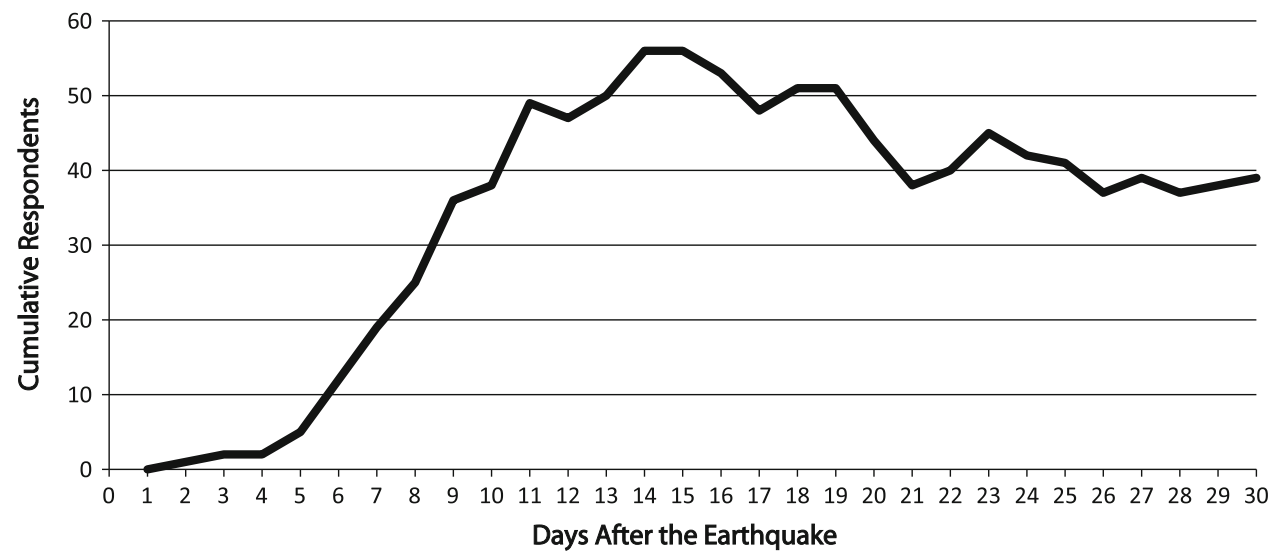

of count data that corrects for multiple comparisons and accounts for dependencies. Because key informants might have a tendency to mention particular themes together, this analysis does not assume that each thematic group is independent. To determine the difference in disaster equipment management difficulty scores between disastertrained and disaster-untrained volunteers, we performed a Wilcoxon rank-sum test for nonparametric data to limit the effect of skewed Likert scale data. Comparison of respondents with and without training was conducted and the medians and means presented. All statistical analyses were conducted at the Orthopaedic Trauma Institute of University of California, San Francisco. Institutional review board approval was obtained before this study.

\section{Results}

Based on the interviews, we identified 10 recurrent themes essential for disaster response and quantified their occurrences: (1) media involvement did not directly impact patient care ("neutral impact of media on patient care"); (2) short-term military involvement supported response teams/individuals ("short-term military involvement"); (3) the necessary yet cumbersome credentialing processes should be improved ("improving the credentialing process"); (4) the AAOS/Orthopaedic Trauma Association (OTA) should facilitate resource and personnel distribution ("AAOS/OTA distribution of resources and personnel"); (5) nontraumatologists/noncredentialed personnel should be limited owing to their negative impact on the overall relief effort ("limiting nontraumatologists/noncredentialed personnel"); (6) volunteers should work with an organized group ("group organization"); (7) volunteers should have "prior disaster experience"; (8) volunteers should have "predisaster training"; (9) volunteers should establish "resource self-sufficiency (supplies, food/water, etc)" on the ground; and (10) volunteers should have "local contacts prior to arrival" (Fig. 2). The most frequently occurring theme, group organization, was discussed more often than all other themes except local contacts before arrival and short-term military involvement $(\mathrm{p}=.170$ and $\mathrm{p}=.169$, respectively, Poisson regression analysis; Table 2). Group organization, local contacts before arrival, and short-term military involvement were the most often discussed of the themes, with a total of 31,22 , and 19 occurrences in the 14 interviews, respectively. Limiting nontraumatologists/noncredentialed personnel was discussed least often among the themes.

In addition to the interview analysis, differences between mean and median disaster management difficulty scores for disaster-trained and disaster-untrained respondents indicate that respondents with prior disaster training reported lower mean difficulty scores for all disaster equipment management tasks compared with the untrained group, except for equipment installation and managing distribution $(11.3 \%$ and $1.43 \%$ increases, respectively). The mean differences for two of the tasks, transport to the treatment site $(19.5 \%$ decrease $)$ and security during storage ( $16.5 \%$ decrease) were statistically significant $(\mathrm{p}=.0397$ and $\mathrm{p}=.0473$, respectively, Wilcoxon rank-sum test). Equipment installation, maintenance, and distribution management had the highest median scores of 2 for both groups (Table 3). Median scores were the same between the groups for all tasks except for transport to treatment site, which was more difficult for untrained respondents compared with trained respondents ( 2 and 1 , respectively).

Estimates of the quantity and proportion of procedures performed indicate that upper extremity (243; $3 \%$ of total) and lower extremity $(1071 ; 14 \%$ of total) guillotine amputations, fasciotomies ( $219 ; 3 \%$ of total), and internal fixations (917; $12 \%$ of total) were frequently performed. A total of at least 7826 procedures were reportedly performed: 4810 primary (61\%) and 3016 revision (39\%) procedures (Table 4). 
Fig. 2 A graph shows the interview-based thematic analysis, including the total number of thematic occurrences for all interviews where each theme represents an essential aspect of the disaster response; AAOS/OTA = American Academy of Orthopaedic Surgeons/ Orthopaedic Trauma Association.

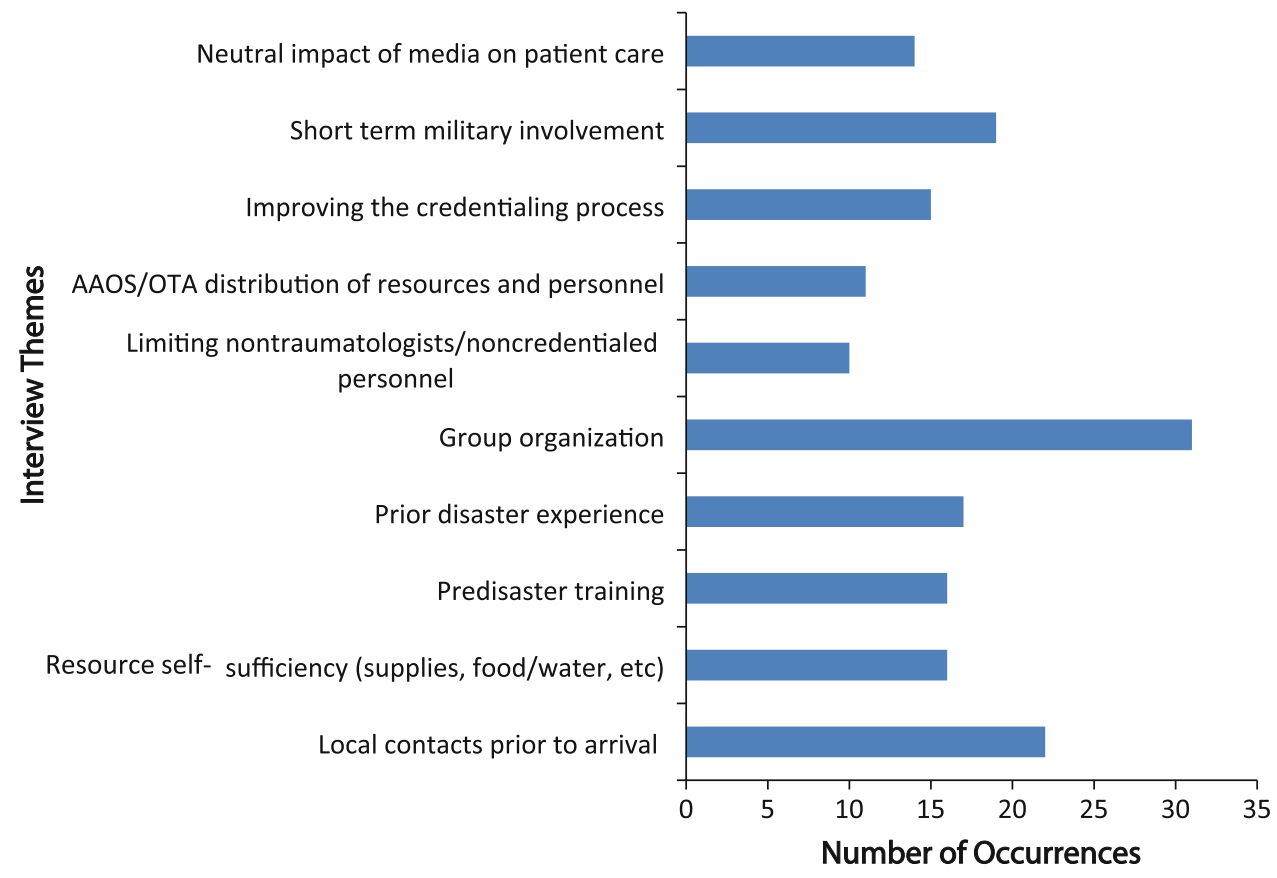

Table 2. Poisson regression analysis of interview themes

\begin{tabular}{ll}
\hline $\begin{array}{l}\text { Interview-based themes essential } \\
\text { for disaster response }\end{array}$ & $\begin{array}{l}\text { Count comparison } \\
\text { (p value)* }\end{array}$ \\
\hline $\begin{array}{l}\text { Local contacts before arrival } \\
\text { Resource self-sufficiency (supplies, } \\
\quad \text { food/water, etc) }\end{array}$ & .170 \\
Predisaster training & $.013^{* *}$ \\
Prior disaster experience & $.045^{* *}$ \\
Group organization & $.016^{* *}$ \\
Limiting nontraumatologists and & - \\
$\quad$ noncredentialed personnel & $.004^{* *}$ \\
AAOS/OTA distribution of resources & $.010^{* *}$ \\
$\quad$ and personnel & $.018^{* *}$ \\
Improving the credentialing process & .169 \\
Short-term military involvement & $.003^{* *}$ \\
Neutral impact of media on patient care
\end{tabular}

* Comparison of thematic count data is relative to the most recurrent theme which was group organization with a total of 31 thematic occurrences from the 14 key informant interviews; **statistically significant $\mathrm{p}<.05$; AAOS/OTA $=$ American Academy of Orthopaedic Surgeons/Orthopaedic Trauma Association.

\section{Discussion}

Although surgical experiences have been described, little is known regarding the needs of and barriers to care faced by volunteer orthopaedic surgeons after major disasters. Therefore, our purpose was to qualitatively assess these needs of and barriers to care faced by orthopaedic surgeons who volunteered in Haiti within 30 days of the earthquake. We (1) identified and compared recurrent interview themes essential to the disaster response; (2) determined the difference in reported disaster equipment management task difficulty between disaster-trained and untrained volunteers; and (3) approximated the quantity of various procedures performed.

This study has several limitations. First, owing to a dearth of related research, the survey and interview tools lack validation and, in addition to the representative key informant selection, were based on the expert opinions of two coauthors (RG and RRC). Nevertheless, the qualitative data obtained will help define potential orthopaedic disaster response measures in the future. Second, the key informants and survey respondents represent only a minority of volunteers. Third, the survey is limited by inherent survey bias such as sampling and recall bias; all volunteers were not captured by the AAOS registry. Fourth, extending the Likert scale to improve interrater reliability [55], and understanding the specific circumstances and indications around the various procedures performed and their outcomes represent potential survey design improvements in the future. Finally, although the number of procedures performed is a conservative approximation, it is likely an underestimate.

Our interview data highlight barriers and opportunities to improve postearthquake orthopaedic care. Group organization, the most recurrent theme (31 occurrences), likely represents the most major opportunity for improvement in future orthopaedic disaster relief. Deficient organization and coordination of efforts are recognized problems of disaster response $[1,35,58]$. From the initial response onward, injured Haitians and relief teams were challenged 
Table 3. Disaster equipment management task difficulty

\begin{tabular}{lllllc}
\hline $\begin{array}{l}\text { Disaster equipment management-related } \\
\text { tasks }\end{array}$ & $\begin{array}{l}\text { Untrained } \\
\text { (median) }\end{array}$ & $\begin{array}{l}\text { Untrained } \\
(\text { mean })\end{array}$ & $\begin{array}{l}\text { Trained } \\
\text { (median) }\end{array}$ & $\begin{array}{l}\text { Trained } \\
\text { (mean) }\end{array}$ & $\begin{array}{l}\% \text { Change } \\
\text { in means }\end{array}$ \\
\hline Plane unloading & 1 & 1.17 & 1 & 1.12 & -4.27 \\
Transporting to treatment site & 2 & 1.69 & 1 & 1.36 & -19.5 \\
Security during transport & 1 & 1.26 & 1 & 1.08 & -14.3 \\
Security during storage at site & 1 & 1.33 & 1 & 1.11 & -16.5 \\
Installing equipment & 2 & 1.68 & 2 & 1.87 & $.0397 *$ \\
Maintaining equipment & 2 & 1.94 & 2 & 1.85 & $.0473 *$ \\
Managing distribution & 2 & 2.10 & 2 & 2.13 & .2817 \\
\hline
\end{tabular}

* Statistically significant $\mathrm{p}<.05$.

Table 4. Procedures performed

\begin{tabular}{|c|c|c|c|c|c|c|}
\hline Procedure & $\begin{array}{l}\text { Primary } \\
\text { (number) }\end{array}$ & $\begin{array}{l}\text { Primary } \\
\text { (\% of total) }\end{array}$ & $\begin{array}{l}\text { Revision } \\
\text { (number) }\end{array}$ & $\begin{array}{l}\text { Revision } \\
\text { (\% of total) }\end{array}$ & $\begin{array}{l}\text { Total } \\
\text { (number) }\end{array}$ & $\begin{array}{l}\text { Total } \\
(\%)\end{array}$ \\
\hline Amputation, lower extremity, guillotine & 534 & 7 & 537 & 7 & 1071 & 14 \\
\hline Amputation, lower extremity, nonguillotine & 426 & 5 & 449 & 6 & 875 & 11 \\
\hline Amputation, upper extremity, guillotine & 105 & 1 & 138 & 2 & 243 & 3 \\
\hline Amputation, upper extremity, nonguillotine & 157 & 2 & 124 & 2 & 281 & 4 \\
\hline External fixation, lower extremity & 864 & 11 & 396 & 5 & 1260 & 16 \\
\hline External fixation, upper extremity & 166 & 2 & 74 & 1 & 240 & 3 \\
\hline External fixation, other & 90 & 1 & 60 & 1 & 150 & 2 \\
\hline Fasciotomy & 105 & 1 & 114 & 1 & 219 & 3 \\
\hline Internal fixation & 781 & 10 & 136 & 2 & 917 & 12 \\
\hline Skin graft & 276 & 4 & 72 & 1 & 348 & 4 \\
\hline Wound débridement & 1306 & 17 & 916 & 12 & 2222 & 28 \\
\hline Total & 4810 & 61 & 3016 & 39 & 7826 & \\
\hline
\end{tabular}

by lack of organized medical support and impaired supplies coordination [33, 45]. Spontaneous unaffiliated volunteers (SUVs) hampered the relief effort, for example, because they lacked disaster response organization of personal safety regulations, immunizations, health and liability insurance, cultural sensitivity and logistics training, and patient follow-up. A lack of organization among relief agencies, furthermore, contributes to these impairments in care provisioning and challenges related to disaster data collection for relief improvement [27, 44]. Using prior in-country contacts (21 occurrences), another recurrent theme, was important for other groups responding to the Haiti earthquake [41]. These contacts can facilitate relief coordination. Finally, despite communication challenges regarding patient transfer to and from military vessels, short-term military involvement (19 occurrences) facilitated equipment, security, and patient management, which was helpful for many volunteers [2, 8]. Therefore, civil-military collaboration, throughout disaster training, planning, and response phases, could augment resource distribution and care in future relief efforts. However, administrative and legal obstructions must be overcome for this collaboration to gain traction.

A minority of respondents reported disaster training, experience, or credentialing, a phenomenon documented in prior disasters and noted soon after the Haiti earthquake $[18,60]$. Conducive schedules among academic volunteers and an interest in disaster preparedness research might account for the substantial number of university faculty respondents. Interview themes and the observed disaster management scores support the importance of prior training and experience for volunteer surgeons who face mass casualties and injuries in a disaster $[25,50]$. Training might have directly contributed to differences observed in storage security and equipment distribution, or indirectly led to logistical assistance if trained volunteers could more easily collaborate with the military $[2,8]$. Collaborating with the military for equipment requiring immediate setup could 


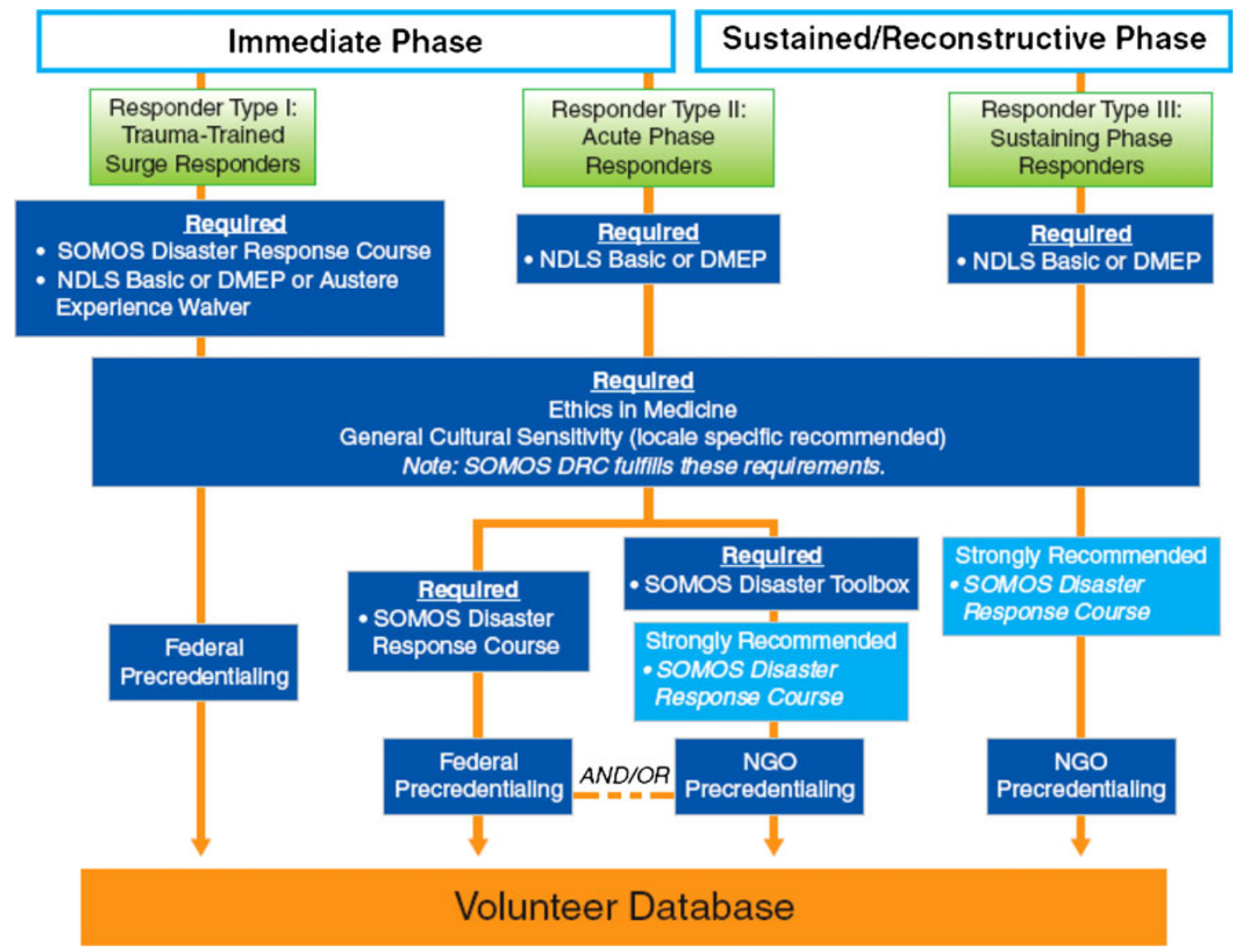

Fig. 3 A flow diagram illustrates the AAOS orthopaedic volunteer disaster preparedness training, certification, and credentialing pathways [10]. (Reprinted with permission by the AAOS from Born CT, Teuscher D, Dowling L. AAOS approves disaster preparedness plan. AAOS Now. 2011;5(8). Available at: http://www.aaos.org/news/

have contributed to the greater difficulty observed with equipment installation for the trained respondents. Additionally, since airport-related delays impeded resource distribution and likely contributed to the observed difficulty with these equipment management tasks [18, 45], some have suggested "pre-positioning" medical and surgical supplies at strategic airfields with "pre-clearance" through international customs [13]. Concerns regarding the intentions, experience, and credentialing of responders to the Haiti earthquake led to labels such as SUVs or "disaster tourists" [58], as in prior disasters [25, 51]. Inexperienced and untrained volunteers were urged to stay home because they lacked security, equipment, patient followup systems, and cultural sensitivity preparedness $[9,18]$. Owing to the perceived importance of disaster training by AAOS and OTA members after the Haiti earthquake, the AAOS developed a disaster preparedness/response platform for their members to prepare for future catastrophic events (Fig. 3) [10]. The AAOS website will have a section aaosnow/aug11/clinical2.asp. (c) 2011 American Academy of Orthopaedic Surgeons.) SOMOS $=$ Society of Military Orthopaedic Surgeons; NDLS = National Disaster Life Support; DMEP $=$ Disaster Management and Emergency Preparedness; DRC $=$ Disaster Response Course; NGO = nongovernmental agencies.

dedicated entirely to disaster preparedness training and credentialing that, in collaboration with the HHS/NDMS and US military, might also function as a database of civilian medical personnel qualified and credentialed as a disaster responder by the federal government. This database could collect surgical data during the disaster as a means of program monitoring and evaluation [13, 43], and facilitate individual civilian responders, supply distribution, and organizational communication.

Guillotine amputations, internal fixations, fasciotomies, and revision procedures, suggestive of inappropriate disaster care, were frequently reported. Although the indications and specific circumstances around these procedures are unknown, some experts and organizations advise against guillotine amputations [19, 25, 47], fasciotomies for acute closed muscle-crush injury [39, 48, 49, 53], and internal fixation [21, 25] in disaster and war settings. In addition, the observed ratio of greater than one revision for every primary amputation suggests higher 
revision rates than those documented in the developed world $(25 \%-30 \%)$ [11, 28, 59]. Limited resource distribution and space, security concerns, myriad complex polytrauma cases, and inadequate disaster training represent a few of the many potential environmental explanations for the observed cases. These circumstances and outcomes require further study to understand the effect of these procedures in resource-poor disaster settings.

Using qualitative interview- and survey-based methods we confirmed that organizational and training barriers to quality surgical care existed in the aftermath of the Haiti earthquake $[4,5,9,13,18,27,45]$. Although disaster training could augment future relief efforts [7, 50], this type of training and disaster procedure outcomes require further study to improve orthopaedic care in future catastrophes.

Acknowledgments We thank the Institute for Global Orthopaedics and Traumatology team including, Thomas Penoyar MD for his initial efforts in coordinating the study, Jesse Shantz MD for his guidance, David Tannenbaum for help with the data analysis, and Theodore Miclau III MD and Peter Trafton MD, for their manuscript revisions and advice.

\section{Appendix 1. Interview questions for orthopaedic surgeon volunteers}

\section{(Expectations)}

What were your predeployment expectations about your trip to Haiti?

What did you base your expectations on? (Previous experience? Peers' experiences? What you read or heard about?)

\section{(Preparedness)}

How did you prepare yourself for departure?

What criteria did you use to identify what supplies or resources to bring?

If you brought a team, what criteria did you use to identify who to bring?

\section{(On the Ground)}

Describe the notable events, positive or negative, that occurred between your arrival and your first operation?

Who or what was serving as the "charge nurse" (ie, managing supplies, personnel, and patient flow) at the facility where you operated?

Who or what was serving as the overall command for how resources and personnel were distributed to various facilities?

\section{(Reflections)}

What would you change about your on-the-ground experience?

If not, why, or what would need to be different for you to volunteer?
What three things would you change if you could?

(Media)

Did you personally document your experience? (ie, social networking site, blog, emails?)

Was there a third-party public response associated with your experience? (ie, article published, social networking?)

- Name (Optional): First Last

- Email (Optional):

- Practice type in the United States: University Faculty, Private Practice, US Military, Retired, Other

- If you selected "other" from the previous question, please specify:

- Affiliation while in Haiti: University, NGO, Governmental/Military, Other

- Name of Affiliate Program:

- Arrival date in Haiti: MM/ DD/ YYYY

- Departure date from Haiti: MM/ DD/ YYYY

\section{References}

1. Abolghasemi H, Radfar MH, Khatami M, Nia MS, Amid A, Briggs SM. International medical response to a natural disaster: lessons learned from the Bam earthquake experience. Prehosp Disaster Med. 2006;21:141-147.

2. Auerbach PS, Norris RL, Menon AS, Brown IP, Kuah S, Schwieger J, Kinyon J, Helderman TN, Lawry L. Civil-military collaboration in the initial medical response to the earthquake in Haiti. N Engl J Med. 2010;362:e32.

3. Bar-On E, Lebel E, Kreiss Y, Merin O, Benedict S, Gill A, Lee E, Pirotsky A, Shirov T, Blumberg N. Orthopaedic management in a mega mass casualty situation: the Israel Defence Forces Field Hospital in Haiti following the January 2010 earthquake. Injury. 2011;42:1053-1059.

4. Bayard D. Haiti earthquake relief, phase two: long-term needs and local resources. N Engl J Med. 2010;362:1858-1861.

5. Benjamin E, Bassily-Marcus AM, Babu E, Silver L, Martin ML. Principles and practice of disaster relief: lessons from Haiti. $M t$ Sinai J Med. 2011;78:306-318.

6. Berman L, Curry L, Gusberg R, Dardik A, Fraenkel L. Informed consent for abdominal aortic aneurysm repair: the patient's perspective. J Vasc Surg. 2008;48:296-302.

7. Born CT, Briggs SM, Ciraulo DL, Frykberg ER, Hammond JS, Hirshberg A, Lhowe DW, O'Neill PA. Disasters and mass casualties: I. General principles of response and management. J Am Acad Orthop Surg. 2007;15:388-396.

8. Born CT, Cullison TR, Dean JA, Hayda RA, McSwain N, Riddles LM, Shimkus AJ. Partnered disaster preparedness: lessons learned from international events. J Am Acad Orthop Surg; 2011: 19(supp11)S44-48.

9. Born CT, France JC, Krieg JC, McAndrew MP, Monchik KO. Disasters offer lessons, opportunities. AAOS Now. 2010; 4(3). Available at: http://www.aaos.org/news/aaosnow/mar10/youraaos2. asp. Accessed March 21, 2012.

10. Born CT, Teuscher D, Dowling L. AAOS approves disaster preparedness plan. AAOS Now. 2011;5(8). Available at: http://www. aaos.org/news/aaosnow/aug11/clinical2.asp. Accessed March 16, 2011.

11. Bourke HE, Yelden KC, Robinson KP, Sooriakumaran S, Ward DA. Is revision surgery following lower-limb amputation a 
worthwhile procedure? A retrospective review of 71 cases. Injury. 2011;42:660-666.

12. Bradley EH, Curry LA, Devers KJ. Qualitative data analysis for health services research: developing taxonomy, themes, and theory. Health Serv Res. 2007;42:1758-1772.

13. Chu K, Stokes C, Trelles M, Ford N. Improving effective surgical delivery in humanitarian disasters: lessons from Haiti. PLoS Med. 2011;8:e1001025.

14. Clover AJ, Rannan-Eliya S, Saeed W, Buxton R, Majumder S, Hettiaratchy SP, Jemec B; British Association of Plastic, Reconstructive, and Aesthetic Surgeons; Medical Emergency Relief International Emergency Response Team to Haiti, January to April of 2010. Experience of an orthoplastic limb salvage team after the Haiti earthquake: analysis of caseload and early outcomes. Plast Reconstr Surg. 2011;127:2373-2380.

15. Corbin JM, Strauss AL. Basics of Qualitative Research: Techniques and Procedures for Developing Grounded Theory: Thousand Oaks, CA: Sage Publications, Inc; 2008.

16. D'Ambrosia RD. Disaster response. Orthopedics. 2010;33:144.

17. Devi S. Helping earthquake-hit Haiti. Lancet. 2010;375:267268.

18. de Vries HJ, Brouwer S, Groothoff JW, Geertzen JH, Reneman MF. Staying at work with chronic nonspecific musculoskeletal pain: a qualitative study of workers' experiences. BMC Musculoskeletal Disorders. 2011;12:126.

19. Dufour D, Korman Jensen S, Owen-Smith M, Salmela J, Stening GF, Zetterstrom B. Surgery for Victims of War. Geneva, Switzerland: ICRC; 1998.

20. Farmer PE, Kim JY. Surgery and global health: a view from beyond the OR. World J Surg. 2008;32:533-536.

21. Giannou C, Baldan M. War Surgery: Working with Limited Resources in Armed Conflict and Other Situations of Violence. Geneva, Switzerland: ICRC; 2009.

22. Ginzburg E, O'Neill WW, Goldschmidt-Clermont PJ, de Marchena E, Pust D, Green BA. Rapid medical relief: Project Medishare and the Haitian earthquake. $N$ Engl J Med. 2010;362: e31.

23. Glaser BG. The constant comparative method of qualitative analysis. Social Problems. 1965;12:436-445.

24. Gooberman-Hill R, Sansom A, Sanders CM, Dieppe PA, Horwood J, Learmonth ID, Williams S, Donovan JL. Unstated factors in orthopaedic decision-making: a qualitative study. $B M C$ Musculoskelet Disord. 2010;11:213.

25. Gosselin RA. War injuries, trauma, and disaster relief. Techniques in Orthopaedics. 2005;20:97-108.

26. Green J, Browne J. Principles of Social Research. Maidenhead, Berkshire, England: Open University Press; 2005.

27. Growth of aid and the decline of humanitarianism. Lancet. 2010;375:253.

28. Harris AM, Althausen PL, Kellam J, Bosse MJ, Castillo R; Lower Extremity Assessment Project (LEAP) Study. Complications following limb-threatening lower extremity trauma. J Orthop Trauma. 2009;23:1-6.

29. Holloway I, Todres L. The status of method: flexibility, consistency and coherence. Qualitative Research. 2003;3:345-357.

30. Ivers LC, Garfein ES, Augustin J, Raymonville M, Yang AT, Sugarbaker DS, Farmer PE. Increasing access to surgical services for the poor in rural Haiti: surgery as a public good for public health. World J Surg. 2008;32:537-542.

31. Jackson CJ, Dixon-Woods M, Eborall H, Kenyon S, ToozsHobson P, Tincello DG. Women's views and experiences of a patient preference trial in surgery: a qualitative study of the CARPET1 trial. Clin Trials. 2010;7:696-704.

32. Kidger J, Murdoch J, Donovan JL, Blazeby JM. Clinical decision-making in a multidisciplinary gynaecological cancer team: a qualitative study. BJOG. 2009;116:511-517.
33. Leahy M. Rebuilding orthopaedics in Haiti. AAOS Now. 2011;5(6). Available at: http://www.aaos.org/news/aaosnow/jun11/youraaos3. asp. Accessed March 21, 2012.

34. Lebel E, Blumberg N, Gill A, Merin O, Gelfond R, Bar-On E. External fixator frames as interim damage control for limb injuries: experience in the 2010 Haiti earthquake. J Trauma. 2011; 71:E128-131.

35. Lee VJ, Low E. Coordination and resource maximization during disaster relief efforts. Prehosp Disaster Med. 2006;21:s8-12.

36. Lhowe DW, Briggs SM. Planning for mass civilian casualties overseas: IMSuRT-International Medical/Surgical Response Teams. Clin Orthop Relat Res. 2004;422:109-113.

37. Lorich DG, Jeffcoat DM, MacIntyre NR, Chan DB, Helfet DL. The 2010 Haiti earthquake: lessons learned? Tech Hand Up Extrem Surg. 2010;14:64-68.

38. Lown BA, Chou CL, Clark WD, Haidet P, White MK, Krupat E, Pelletier S, Weissmann P, Anderson MB. Caring attitudes in medical education: perceptions of deans and curriculum leaders. J Gen Intern Med. 2007;22:1514-1522.

39. Matsuoka T, Yoshioka T, Tanaka H, Ninomiya N, Oda J, Sugimoto H, Yokota J. Long-term physical outcome of patients who suffered crush syndrome after the 1995 Hanshin-Awaji earthquake: prognostic indicators in retrospect. J Trauma. 2002; 52:33-39.

40. McCann PD. Haiti: how to respond? Am J Orthop (Belle Mead NJ). 2010;39:117.

41. McCunn M, Ashburn MA, Floyd TF, Schwab CW, Harrington P, Hanson CW 3rd, Sarani B, Mehta S, Speck RM, Fleisher LA. An organized, comprehensive, and security-enabled strategic response to the Haiti earthquake: a description of pre-deployment readiness preparation and preliminary experience from an academic anesthesiology department with no preexisting international disaster response program. Anesth Analg. 2010;111:1438-1444.

42. McIntyre T, Hughes CD, Pauyo T, Sullivan SR, Rogers SO Jr, Raymonville M, Meara JG. Emergency surgical care delivery in post-earthquake Haiti: Partners in Health and Zanmi Lasante experience. World J Surg. 2011;35:745-750.

43. McQueen KA, Parmar P, Kene M, Broaddus S, Casey K, Chu K, Hyder JA, Mihailovic A, Semer N, Sullivan SR, Weiser T, Burkle FM Jr. Burden of surgical disease: strategies to manage an existing public health emergency. Prehosp Disaster Med. 2009;24(suppl 2): s228-231.

44. Morton M, Levy JL. Challenges in disaster data collection during recent disasters. Prehosp Disaster Med. 2011;26:196-201.

45. Pape JW, Johnson WD Jr, Fitzgerald DW. The earthquake in Haiti: dispatch from Port-au-Prince. N Engl J Med. 2010;362:575-577.

46. Redmond AD; WHO. Needs assessment of humanitarian crises. BMJ. 2005;330:1320-1322.

47. Redmond AD, Mahoney PF, Ryan JM, Macnab C, eds. $A B C$ of Conflict and Disaster: Malden, MA: Blackwell Publishing Ltd; 2006.

48. Reis ND, Better OS. Mechanical muscle-crush injury and acute muscle-crush compartment syndrome: with special reference to earthquake casualties. J Bone Joint Surg Br. 2005;87:450-453.

49. Reis ND, Michaelson M. Crush injury to the lower limbs: treatment of the local injury. J Bone Joint Surg Am. 1986;68:414-418.

50. Roy N, Shah H, Patel V, Bagalkote H. Surgical and psychosocial outcomes in the rural injured: a follow-up study of the 2001 earthquake victims. Injury. 2005;36:927-934.

51. Roy N, Shah H, Patel V, Coughlin RR. The Gujarat earthquake (2001) experience in a seismically unprepared area: community hospital medical response. Prehosp Disaster Med. 2002;17:186-195.

52. Sarani B, Mehta S, Ashburn M, Gupta R, Dombroski D, Raymonville M, Schwab CW. Evolution of operative interventions by two university-based surgical teams in Haiti during the first month following the earthquake. Prehosp Disaster Med. 2011;26: 206-211. 
53. Sever MS, Erek E, Vanholder R, Akoglu E, Yavuz M, Ergin H, Turkmen F, Korular D, Yenicesu M, Erbilgin D, Hoeben H, Lameire N. Clinical findings in the renal victims of a catastrophic disaster: the Marmara earthquake. Nephrol Dial Transplant 2002;17:1942-1949.

54. Springgate BF, Allen C, Jones C, Lovera S, Meyers D, Campbell L, Palinkas LA, Wells KB. Rapid community participatory assessment of health care in post-storm New Orleans. Am J Prev Med. 2009;37(6 suppl 1):S237-243.

55. Streiner DL, Norman GR. Health Measurement Scales: A Practical Guide to Their Development and Use. Oxford, United Kingdom: Oxford University Press; 2008.
56. Stuart JJ, Johnson DC. Air Force disaster response: Haiti experience. J Surg Orthop Adv. 2011;20:62-66.

57. Sullivan SR, Taylor HO, Pauyo T, Steer ML. Surgeons' dispatch from Cange, Haiti. N Engl J Med. 2010;362:e19.

58. Van Hoving DJ, Wallis LA, Docrat F, De Vries S. Haiti disaster tourism: a medical shame. Prehosp Disaster Med. 2010;25:201-202.

59. Wood MR, Hunter GA, Millstein SG. The value of revision surgery after initial amputation of an upper or lower limb. Prosthet Orthot Int. 1987;11:17-20.

60. Zoraster RM. Barriers to disaster coordination: health sector coordination in Banda Aceh following the South Asia Tsunami. Prehosp Disaster Med. 2006;21:s13-18. 